\title{
Impact of Dairy Enterprises on Employment Creation and Income Generation in Hadiya Zone, Ethiopia
}

\author{
Abriham Ababiya ${ }^{1}$, Jema Haji ${ }^{1}$, Endrias Geta ${ }^{2} \&$ Lemma Zemedu $^{3}$ \\ ${ }^{1}$ School of Agricultural Economics and Agribusiness, Haramaya University, Ethiopia \\ ${ }^{2}$ South Agricultural Research Institute, Ethiopia \\ ${ }^{3}$ Ethiopian Institute of Agricultural Research, Debrezeit Center, Ethiopia \\ Correspondence: Abriham Ababiya, School of Agricultural Economics and Agribusiness, Haramaya University, \\ Ethiopia. Tel: 251-913-258-568. E-mail: abrahamababiya2@gmail.com
}

\author{
Received: July 17, 2019 Accepted: September 17, 2019 Online Published: October 30, 2019 \\ doi:10.5539/sar.v8n4p72 URL: https://doi.org/10.5539/sar.v8n4p72
}

\begin{abstract}
This study sought to examine the impact of dairy enterprises on employment creation and income generation in Hadiya zone, Ethiopia. Data were collected from 385 randomly selected household heads, three FGDs participants and five key informants' interviews. Data were analyzed using descriptive statistics and propensity score matching. The survey results showed that out of 385 sampled household heads $126(32.5 \%)$ were members and the remaining $259(67.5 \%)$ were non-members of micro and small dairy enterprises. The propensity score matching result shows that being member had significant positive impact on members' employment creation and income generation. The result revealed that the membership resulted in average increment of household's annually employment creation by about 4 persons (33.98\%) and income generation by Birr 12,339.00 (32.57\%). The result showed that membership in dairy enterprises had a significant and positive impact on employment creation and income generation. The impact estimates were found to be insensitive to unobserved selection bias. It is, therefore, essential to expand and strengthen development of dairy enterprises and the membership of households in dairy enterprises to increase employment creation and income generation of members.
\end{abstract}

Keywords: dairy enterprises, employment creation, income generation, propensity score matching

\section{Introduction}

The government of Ethiopia implements multi-dimensional policies and strategies to ensure rapid and sustainable growth and development in the past three decades through enterprise development. From those main concrete pillars of economic sectors, enterprises development is one of the most important economic sectors which plays great role in diversifying economic activities and used as a bridge to transform the economy of the country from agriculture to industrialization. To realize the role of enterprises in the socio-economic development of the country, the government of Ethiopia introduced the first enterprise development strategy in 1997 to create broad base, competitive and convenient sector for industry development. The enterprises are classified based on paid up capital in to three levels of development stages (micro, small and large) and five sectors (manufacturing, trade, construction, service and agriculture) (FeMSEDA, 1997).

The role of enterprises in employment and income generation is increasingly recognized and has become a major playing field for policy makers and donors with dual objectives of enhancing growth and reducing poverty. The enterprise sector has been considered by academicians and policy makers as an engine of economic growth, poverty reduction, and social development due to its effect on employment and income generation, import substitution, springboard to entrepreneurship and industrialization, base for medium and large industries and distribution of their products through linkage and sub-contracting, and income distributions among different sections of the society (Hailay et al., 2014). Enterprises play key role in stimulating other sectors of the economy such as manufacturing, trade, construction, service and agriculture by increasing productivity through providing inputs and creating demand for outputs (MoFED, 2016).

According to Yaregal (2018) the enterprises sector is characterized by highly diversified activities which can create employment opportunities for a substantial segment of the population. They realize a modest standard of living through curbing unemployment and facilitating the environment for new job seekers and self-employment 
requires a direct intervention and support of the government. This sector is also described as the national home of entrepreneurship. It provides the environment enabling entrepreneurs to exercise their talents to the full and to attain their goals. In all the successful economies, enterprises are seen as an essential springboard for growth and job creation at large (Fikirte and Endrias, 2015).

In developing countries, enterprises have also a crucial role because of their potential contributions to improvement of income distribution, employment creation, industrial development, rural development, and export growth (Zemenu, 2014). Both developed as well as developing countries are taking extreme benefits from enterprises that enable them to accelerate their economy. However, in Ethiopia, enterprises were found small compared to other African countries due to lack of access to markets, finance, working premises, supply of raw material, lack of sufficient capital, business information, business premises, the acquisition of skills and managerial expertise, access to modern technology and regulatory environments (Tariku, 2018 ). Similarly, Tomas et al. (2018) found that the average annual growth of the surveyed six major towns in Ethiopia was 9\% since start-up and $69 \%$ of these enterprises did not grow due to the problems of inadequate formal sources of credit.

In addition, a study by Hailay et al. (2014) reported that most enterprises did not grow and remain at their initial level due to different internal and external factors like, gender of manager, type of sector, managerial skills, amount of initial capital, access to training, access to market, consultancy service, access to premises, access to infrastructures, access to credit, insufficient technology and high cost of input. Enterprises are the main source of rapid economic growth and the basic transformer of the structure of economic system from agriculture to industrialization. These makes enterprises a major area of concern for government and NGOs with the objectives of investing in human capital, employment creation, saving promotion, asset building, income generation and income inequality reduction, import substitution, innovation etc. However, the intense studies in both academic and policy making circles about the impacts of dairy enterprises on employment creation and income generation were not addressed in the country in general and the study area in particular. This study deals with the agricultural sector enterprises engaged in milk production in the study area. The impact of these dairy enterprises on employment creation and income generation in Hadiya zone is the focus of this study.

\section{Methods}

\subsection{Study Area}

The study area Hadiya zone is found in the Southern Nation's Nationalities and People's Region (SNNPR) of Ethiopia. It is located at a distance of $232 \mathrm{~km}$ away from the Addis Ababa, capital city of the country, to south and $180 \mathrm{~km}$ away from regional capital city, Hawassa to North West. The estimated total area of the zone is $346,958.5$ hectares. It is characterized by temperate type of climate with daily temperature ranging from $18 \mathrm{c}$ to $27 \mathrm{c}$, and it is located 1900 meters above sea level. It has low to high rainy season for seven months from February to August and for the remaining five months from September to January have dry air condition throughout the year. The total population of the zone as per the population projection of Ethiopia for all regions at woreda level from 2014-2017 was estimated to be male 846,852 (49.5\%) and female 863,960 (50.5\%) the total of 1,710,812 hard-working, peace-full, multi-ethnic and religious people are found. The zone has 10 woredas and two town administrations. Hosanna town is the head quarter of the zone.

Mixed farming, business activities public and private sectors employments are the dominant economic activities in the zone. Farmers in the study area practice mixed farming system, which is mainly characterized by the rearing of different types of livestock like cattle, sheep, and goat and production of multiple agricultural products such as cereals (wheat, teff, maize, barley and bean), fruits and vegetables. The area is specialized in wheat production and its productivity is about 65 quintals per hectare. In addition, some cash crops like khat and coffee are also produced. The geographical location of the study area is given in Figure 1 below. 


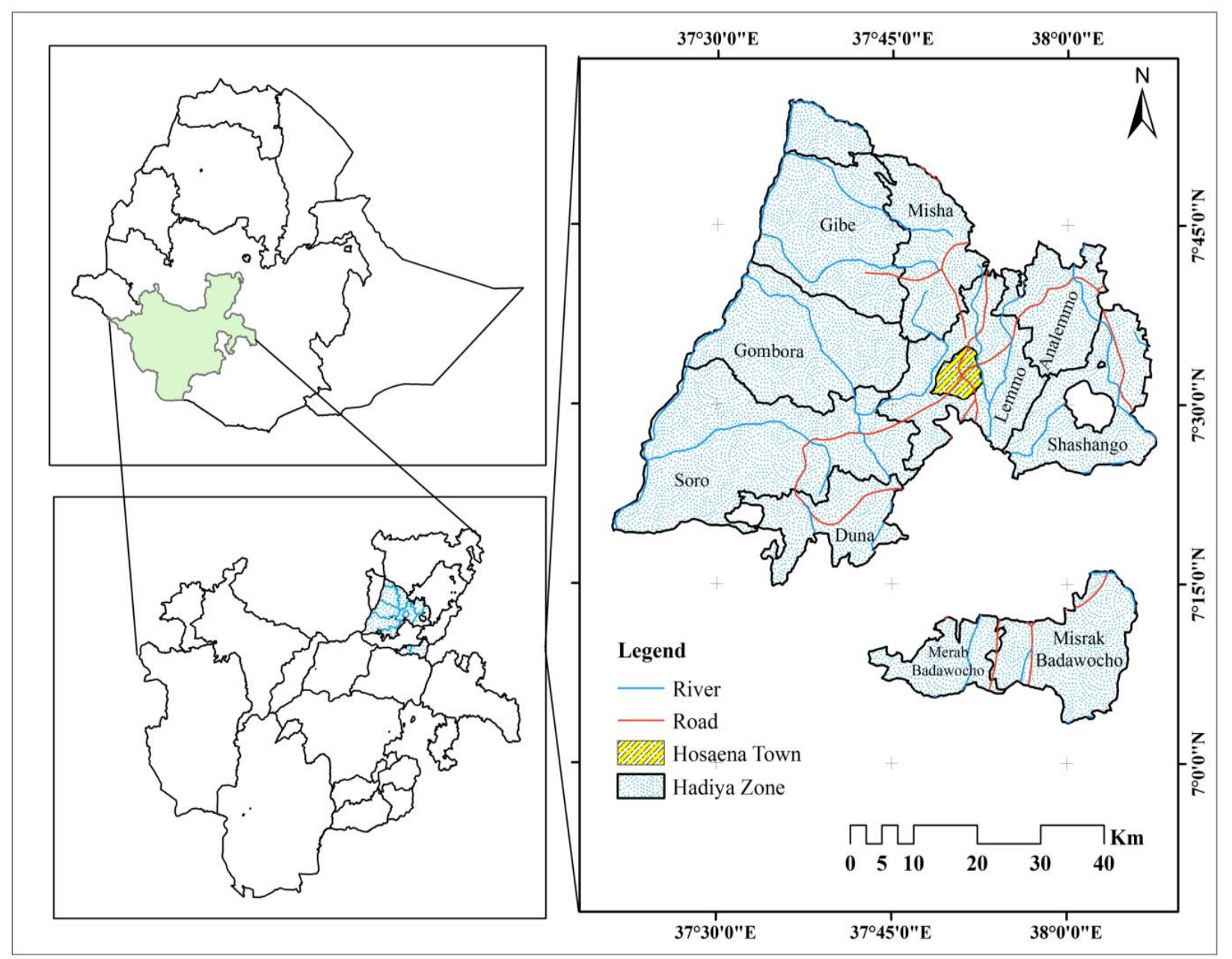

Figure 1. Location map of the study area

Source: Clipped from EthioGIS I. www.walris.wlrc-eth.org

\subsection{Sampling Procedure}

To evaluate the impact of dairy enterprises development on employment creation and income generation, the study used data collected at household level. For evaluation of the impacts of dairy enterprises development on employment creation and income generation, member and non-member household heads were included in the study based on the following sampling work frame. Accordingly, to select the representative samples from the population, this study employed multi-stage with combination of different sampling procedures.

In the first step three woredas namely, Lemmo, Analemmo and Misha were randomly selected from ten woredas in the zone. In the second step, a total of two kebeles from each selected woredas were randomly selected. Following this, six kebeles were randomly selected and household heads within the six kebeles were stratified into member and non-member groups. From those six kebeles 126 member household heads and 259 non-member household heads a total of 385 households were selected by taking household head lists of their names from the kebeles. 
Table 1. Sampling distribution of households

\begin{tabular}{llll}
\hline Population division criteria & Household heads & Proportion (percentage) & Sample size \\
\hline Members & 11850 & 32.5 & 126 \\
Non-members & 24612 & 67.5 & 259 \\
Total & 36462 & 100 & 385 \\
\hline
\end{tabular}

Source: Own design based on Hadiya zone enterprises development office (2016/17)

To determine the sample size for impact evaluation of dairy enterprises development on employment creation and income generation, this study used simplified formula provided by Kothari (2004) to determine the required sample size at $95 \%$ confidence level, estimated variance in the population $50 \%$ and margin of error $5 \%$.

$$
\mathrm{n}=\frac{\mathrm{Z}^{2} \mathrm{pq}}{\mathrm{e}^{2}}=\frac{1.96^{2}(0.5)(0.5)}{(0.05)^{2}}=385
$$

Where, $n$ is desired sample size; $Z$ is values of standard variant at $95 \%$ confidence interval $(Z=1.96)$. $e$ is desired level of precision; $p$ is the estimated proportion of an attribute that is present in the population, and $q$ is 1 -p. The value of $\mathrm{Z}$ is found in the statistical tables which contain the area under normal curve. $P$ is the estimated proportion of an attribute present in the population with the value of 0.5 as suggested by Israel (1992) to get the desired minimum sample size of households at $95 \%$ confidence level. Accordingly, a sample of 385 household heads were selected from six kebeles using random sampling with probability proportional to size as shown in Table 1 above. Qualitative data were also collected by using five key informants' interviews and three focus groups discussion (FGDs) participants.

\subsection{Types of Data and Data Collection Methods}

The study used both primary and secondary data collected from various sources. The primary data were collected from the sample member and non-member household heads through structured questionnaire using interview supported by key informants' interview, focus group discussions and personal observation using checklists which are pre-tested prior to their use. Secondary data were obtained from published books and journal articles, as well as unpublished annual reports and records from government offices and other relevant organizations. All data collection processes are completed under close supervision of the researcher.

\subsection{Data Analysis}

The study employed both descriptive statistics and econometric model. The econometric model called Propensity Score Matching (PSM) was employed to evaluate the impacts of participation in dairy enterprises on employment creation and income generation. Based on Rosenbaum and Rubin (1983), propensity score can be defined as the conditional probability of receiving a treatment given pre-treatment characteristics. Let $Y_{i}^{\mathrm{T}}$ and $Y_{i}{ }^{C}$ are the outcome variable for participant (members in dairy enterprises) and non-participant (non-members in dairy enterprises) respectively. The difference in outcome between treated and control groups can be seen from the following mathematical equation:

$$
\Delta_{i}=Y_{i}^{T}-Y_{i}^{C}
$$

Where

$Y_{i}^{T}$ is outcome of treatment (for household participate in dairy enterprises)

$Y_{i}^{C}$ is outcome of the non-participant (for household non-participate in dairy enterprises),

$\Delta_{i}$ is change in the outcome as a result of treatment for household participate in dairy enterprises

Equation (3) be expressed in causal effect notational form, by assigning $D_{i}=1$ as a treatment variable taking the value of 1 if the household received the treatment and 0 otherwise. Then the Average Treatment Effect (ATE) of a household $i$ can be written as:

$$
A T E=E\left(Y_{i}^{T} \mid D_{i}=1\right)-E\left(Y_{i}^{C} \mid D_{i}=0\right)
$$

Where

ATE is Average treatment effect, which is the effect of treatment on the outcome variables 
$E\left(Y_{i}^{T} \mid D_{i}=1\right)$ is Average outcomes for household, with treatment, if he/she would participant $\left(D_{i}=1\right)$.

$E\left(Y_{i}^{C} \mid D_{i}=0\right)$ is Average outcome of untreated, when he/she would non-participant, or absence of treatment $\left(D_{i}=0\right)$.

The Average Effect of Treatment on the Treated (ATT) for the sample households is given:

$$
A T T=E\left(Y_{i}^{T}-Y_{i}^{C} \mid D_{i}=1\right)=E\left(Y_{i}^{T} \mid D_{i}=1\right)=E\left(Y_{i}^{C} \mid D_{i}=1\right)
$$

The fundamental evaluation problem in evaluation of impact is that it is impossible to observe a person's outcome for with and without treatment at the same time. While the post-intervention outcome $E\left(Y_{i}^{T} \mid D_{i}=1\right)$

is possible to observe, however, the counterfactual outcome of the $i^{\text {th }}$ household when she/he does not use the treatment is not observable in the data. The effectiveness of matching estimators as a feasible estimator for impact evaluation depends on conditional independence assumption (CIA) and assumption of common support (ACS). There are different matching estimators were used in the estimation process of ATT in order to make sure that the results obtained are robust. However, the most commonly applied steps of implementation of propensity score match are discussed below.

Nearest neighbor matching: An individual from a comparison group is chosen as a matching partner for a treated individual that is closest in terms of propensity score (Caliendo and Kopeinig, 2008). That is, each person in the treatment group chooses individual(s) with the closest propensity score to them. Nearest-neighbor matching can be done with or without replacement. In the case of with replacement, an untreated individual can serve more than once as a match, where as it is considered only once in the case of without replacement. Nearest nearest-neighbor matching with replacement increases the average quality of matching and decreases precision of estimation while the reverse is true in the case of nearest nearest-neighbor without replacement (Caliendo and Kopeinig, 2008). Nearest neighbor with replacement is preferred to without when there are big differences between treated and untreated groups to reduce the risk of bad matching.

Kernel matching: In kernel matching, each person in the treatment group is matched to a weighted sum of individuals who have similar propensity score with greatest weight being given to people with closer scores. All treated units are matched with a weighted average of all controls with weights which are inversely proportional to the distance between the propensity scores of treated and controls. The most common approach is to use the normal distribution (with a mean of zero) as a kernel, where the weight attached to a particular comparator is proportional to the frequency of the distribution for the difference in scores observed (Caliendo and Kopeinig, 2008).

Caliper matching: If the closest neighbor is far away, the nearest neighbor matching produces bad matches, and in such situation caliper matching algorithm is used. In caliper matching an individual from the comparison group is chosen as a matching partner for a treated individual that lies within a given caliper (propensity score range) and is closest in terms of propensity score (Caliendo and Kopeinig, 2008). If the dimension of the neighbor is very small, it is possible that some treated units are not matched because the neighbor does not contain a control unit. But, the smaller the size of the neighbor the better is the quality of the matches.

Radius matching: Each treated unit is matched only with the control units whose propensity score falls into a predefined neighborhood of the propensity score of the treated unit. If the dimension of the neighborhood (i.e., the radius) is set to be very small, it is possible that some treated units are not matched because the neighborhood does not contain control units. On the other hand the smaller the size of the neighborhood the better the quality of the matches (Caliendo and Kopeinig, 2005).

In this study, logit model was used to predict the probability of each household being member in the dairy enterprises as a function of observed household characteristics used sample of the dairy enterprises members and non-members. In the logit model the dependent variable was membership, which assumed the value of 1 , if a household head is member in dairy enterprises and 0 otherwise. The explanatory variables used in the model are age of household head, educational level of household heads, farming experience of household heads, access to training, distance to market, soil fertility status, household size, sex of household head, access to formal credit, landholding size, market information, off/non-farm income, livestock holding and membership to association. 
The outcome variables in PSM model were specified as total annual employment created by household's measured in terms of number and the amount of household's total annual income in Birr was taken as the outcome variables.

Testing the matching quality: This is checking whether the matching procedure can balance the distribution of different variables or not. Since we are conditioning on propensity score estimation is not to obtain a precise prediction of selection into treatment, but rather to balance the distributions of relevant variables in both groups. While there are different procedures available to check, the basic aim of all of them is to compare before and after matching and if there still exists any difference after conditioning on propensity score. If the differences exist, there is an indication of incomplete matching and suggests remedial for actions (Caliendo and Kopeinig, 2008).

Sensitivity analysis: The final step in the implementation of PSM is checking the sensitivity of the estimated results (Caliendo and Kopeining, 2005). Matching method is based on the CIA, which states that the evaluator should observe all variables that are simultaneously influencing the participation decision and outcome variables. The estimation of treatment effects with matching estimators is based on the selection at observables assumption. However, a hidden bias might arise if there are unobserved variables which affect assignment into treatment and the outcome variable simultaneously which abolish the CIA. To check the sensitivity of the estimated ATT with respect to deviation from the CIA, it is suggested that the use of Rosenbaum bounding approach is appropriate (Rosenbaum, 2002).

\section{Results and Discussion}

\subsection{Descriptive Results}

The survey results showed that out of 385 sampled household heads, $126(32.5 \%)$ were members and the remaining $259(67.5 \%)$ were non-members. From total sample household heads, the majority of them (74\%) were male-headed (the corresponding figures are $85 \%$ and $69 \%$ for members and non-members respectively). The figures show that enterprises membership is dominated by male headed households. This could be attributed to various reasons, which could be due to the weak economic position of female headed households including limited access and use of information due to cultural barriers in the social position. This might prevent female headed households from being member in dairy enterprises.

The mean age of the household heads was 32 years with a minimum of 25 years and a maximum of 71 years. The mean age of the member household heads was 31 years, whereas, that of the non-member household heads was 34 years. The result depicts that the household heads found both in member and non-member category were found to be in active working age. Education level of household heads varies among the member and non-member households. About $21.3 \%$ member household heads were illiterate and $78.7 \%$ were literate whereas, $26.5 \%$ of non-member household heads were illiterate and $73.5 \%$ were literate.

The land holding size among both members and non-members group indicates that dairy enterprises members has small land size than non-members. From the member group $48.29 \%$ household heads have land size below one hectare and $51.71 \%$ of household heads have land size above one hectare. In other hand the land holding size for non-member group $27.2 \%$ household heads have land size below one hectare and $72.8 \%$ of household heads have land size above one hectare. Based on the land size possessed by non-member household heads respondent they are better than member of dairy enterprises in the study area.

The average household size of the sample household heads in the study area had large average household size of six persons with high mean total dependency ratio of 1.34 . The average household size for member household heads was 7.34 persons while it was 5.06 persons for non-member household heads. When we compared the average household size between members and non-members, household heads the member had higher household size than household heads that did not member in dairy enterprises. From this we can conclude that, household size is the determinant factor of membership in dairy enterprises in the study area.

The mean livestock holding in Tropical Livestock Unit (TLU) of the sample household heads was 6.45, where the minimum was 0 and the maximum was 32 . The mean livestock holding for member households was 4.62 TLU and it was 8.29 TLU for non-member household heads. The member household heads have less livestock holding than non-member household heads. Therefore, the mean comparison for the two groups showed that the difference between the groups with regard to livestock holding. This means household heads with low livestock holding encouraged being member in dairy enterprises than the household heads owed large number of livestock.

\subsection{Econometric Results}

PSM method was used to evaluate the impact of membership to dairy enterprises on employment creation and 
income generation. Prior to the matching analysis, members significantly differed from non-members in most characteristics. According to the results, the imbalance between the members and non-members samples in propensity score, reduced much below $10 \%$ after matching; and the no case was significantly different from zero $(\mathrm{P}<0.01)$. This indicated that all differences in means between members and non-members had been removed through matching in the initial period (before member in dairy enterprises). The process of matching thus creates a high degree of covariate balance between the members and non-members samples that were used in the estimation procedure.

There are some important tasks to be carried out before conducting the matching exercise. First, we estimate predicted values of treatment participation (propensity score) for all the sample household heads (both member and non-member groups). Second, a common support condition should be imposed on the propensity score distributions of member household heads and non-member household heads which helps to identify common support area both members and non-members that their propensity score fall inside the interval. Thirdly, discard observations whose predicted propensity scores fall outside the range of the common support region. Fourth, conducting a sensitivity analysis to check the robustness of the estimation (whether the hidden bias affects the estimated ATT or not).

As shown below in Table 2, among members, the predicted propensity scores range from 0.0136 to 0.9644 , with a mean of 0.6454 . Among non-members, they range from 0.0007 to 0.8844 , with a mean score of 0.1718 . Thus, the common support assumption is satisfied in the region [0.0136 to 0.8844 ]. In other words, households whose estimated propensity scores are less than 0.0136 and larger than 0.8844 were not considered for the matching exercise. As a result of this restriction 16 member households were excluded from the analysis.

Table 2. Distribution of estimated propensity scores

\begin{tabular}{llllll}
\hline Group & Observation & Mean & Std. Dev. & Min & Max \\
\hline Total observation & 369 & 0.3263 & 0.3231 & 0.0007 & 0.9644 \\
Members & 110 & 0.6454 & 0.2244 & 0.0136 & 0.9644 \\
Non-members & 259 & 0.1718 & 0.2396 & 0.0007 & 0.8844 \\
\hline
\end{tabular}

Source: Author's survey data (2016/17)

The choice of matching estimator was conducted based on three different criteria as proposed by Dehejia and Wahba (2002). After obtaining the predicted values conditional on the observable covariates (p-score) from logit estimation, matching was done using matching algorithm which is selected among the commonly used matching methods (kernel matching, nearest neighbour matching, calliper and radius matching) based on the best fit matching algorithm selection criteria: estimator which have low pseudo-R2, large matched sample size, large number of insignificant variables after matching and mean standard bias between three and five. Thereafter, the estimation results and discussion are the direct outcomes of the nearest neighbour (4) matching algorithm. 
Table 3. Matching performance of different estimators

\begin{tabular}{lllll}
\hline Matching estimator & \multicolumn{3}{l}{ Performance criteria } & \\
\cline { 2 - 5 } & Pseudo-R & $\begin{array}{l}\text { Matched } \\
\text { sample size }\end{array}$ & $\begin{array}{l}\text { Mean } \\
\text { standard bias }\end{array}$ & $\begin{array}{l}\text { Number of significant } \\
\text { variables after matching }\end{array}$ \\
\hline Kernel Matching & & & & \\
Band width of 0.1 & 0.031 & 369 & 6.0 & 0 \\
Band width of 0.25 & 0.020 & 369 & 7.5 & 0 \\
Band width of 0.5 & 0.054 & 369 & 14.0 & 0 \\
Nearest Neighbour Matching & & & & \\
Neighbour 1 & 0.037 & 369 & 8.1 & 1 \\
Neighbour 2 & 0.031 & 369 & 9.4 & 1 \\
Neighbour 3 & 0.018 & 369 & 6.0 & 0 \\
Neighbour 4 & 0.013 & 369 & 5.0 & 0 \\
Neighbour 5 & 0.017 & 369 & 6.2 & 0 \\
Calliper Matching & & & & \\
Band width of 0.1 & 0.037 & 369 & 9.3 & 1 \\
Band width of 0.25 & 0.037 & 369 & 9.3 & 1 \\
Band width of 0.5 & 0.037 & 369 & 9.3 & 1 \\
Radius Matching & & & & \\
Band width of 0.1 & 0.434 & 369 & 48.1 & 5 \\
Band width of 0.25 & 0.434 & 369 & 48.1 & 5 \\
Band width of 0.5 & 0.434 & 369 & 48.1 & 5 \\
\hline
\end{tabular}

Source: Author's survey data (2016/17), Nearest Neighbour (4) matching was the best matching.

After selecting the best performing matching algorithm, the next task is to check the balancing of propensity score and covariate using different procedures by applying the selected matching algorithm [nearest neighbour (4) matching in my own case]. The values of Pseudo- $\mathrm{R}^{2}$ and LR Chi-square, before and after matching, can be used as indices for the fulfillment of the balancing requirement. A low Pseudo-R2 value shows that member households do not have much distinct characteristics overall and as such finding a good match between member and non-member households becomes simple. The low value of pseudo- $\mathrm{R}^{2}$ and the insignificant LR Chi-square after matching supported the hypothesis that both groups have the same distribution in covariates after matching. This implies that we have found a comparable group of members with non-members on employment creation and income generation based on similar covariates. The main intention of estimating propensity score is to balance the distributions of relevant variables in both groups. The balancing powers of the estimations are ensured by following testing methods (Table 4). 
Table 4. Balancing test for covariate

\begin{tabular}{|c|c|c|c|c|c|c|c|c|c|}
\hline \multirow[t]{2}{*}{ Variable } & \multirow[t]{2}{*}{ Sample } & \multicolumn{2}{|l|}{ Mean } & \multirow{2}{*}{$\begin{array}{l}\% \\
\text { bias }\end{array}$} & \multirow{2}{*}{$\begin{array}{l}\% \\
\text { Bias }\end{array}$} & \multirow[t]{2}{*}{ reduction } & \multicolumn{2}{|l|}{ t-test } & \multirow[t]{2}{*}{$\mathrm{V}(\mathrm{T}) / \mathrm{V}(\mathrm{C})$} \\
\hline & & Member & Non-member & & & & $\mathrm{t}$ & $p>/ t /$ & \\
\hline \multirow[t]{2}{*}{ Pscore } & Unmatched & 0.6454 & 0.6408 & 2.0 & & & 0.16 & 0.871 & 1.05 \\
\hline & Matched & 0.6101 & 0.6079 & 0.9 & 74.6 & & 0.07 & 0.941 & 0.99 \\
\hline \multirow[t]{2}{*}{ AGE } & Unmatched & 5.7880 & 6.3480 & -12.0 & & & -0.95 & 0.344 & 0.88 \\
\hline & Matched & 5.6405 & 6.5034 & -18.4 & -59.9 & & -1.33 & 0.185 & 0.74 \\
\hline \multirow[t]{2}{*}{ EDU } & Unmatched & 2.4640 & 2.5360 & -7.7 & & & -0.59 & 0.553 & 1.30 \\
\hline & Matched & 2.4775 & 2.4572 & 2.2 & 66.5 & & 0.15 & 0.880 & 1.18 \\
\hline \multirow[t]{2}{*}{ TLU } & Unmatched & 5.9760 & 6.0080 & -1.0 & & & -0.08 & 0.938 & 1.18 \\
\hline & Matched & 6.0991 & 5.6734 & 13.2 & 44.2 & & 1.00 & 0.317 & 1.35 \\
\hline \multirow[t]{2}{*}{ OFAM } & Unmatched & 13730 & 13528 & 17.0 & & & 1.22 & 0.222 & $1.50^{*}$ \\
\hline & Matched & 13282 & 13169 & 5.5 & 86.7 & & 0.44 & 0.661 & 0.79 \\
\hline \multirow[t]{2}{*}{ FERTILITY } & Unmatched & 0.6960 & 0.6560 & 8.6 & & & 0.67 & 0.501 & . \\
\hline & Matched & 0.7297 & 0.7432 & -2.9 & -40.2 & & -0.23 & 0.820 & . \\
\hline \multirow[t]{2}{*}{ EXPRIENCE } & Unmatched & 2.1120 & 2.080 & 2.9 & & & 0.24 & 0.808 & $1.70^{*}$ \\
\hline & Matched & 2.1351 & 2.1712 & -3.3 & 0.5 & & -0.25 & 0.802 & . \\
\hline \multirow[t]{2}{*}{ TRAIN } & Unmatched & 0.7040 & 0.7760 & -15.2 & & & -1.30 & 0.196 & . \\
\hline & Matched & 0.7027 & 0.7612 & -12.4 & 90.3 & & -0.98 & 0.327 & . \\
\hline \multirow[t]{2}{*}{ MKT } & Unmatched & 0.3120 & 0.368 & -11.7 & & & -0.93 & 0.352 & . \\
\hline & Matched & 0.3243 & 0.2950 & 6.1 & 61.1 & & 0.47 & 0.639 & . \\
\hline \multirow[t]{2}{*}{ FAMSIZE } & Unmatched & 0.9440 & 0.9520 & -2.1 & & & -0.28 & 0.777 & . \\
\hline & Matched & 0.9369 & 0.93243 & 1.2 & 81.8 & & 0.14 & 0.893 & . \\
\hline \multirow[t]{2}{*}{ GENDER } & Unmatched & 0.2720 & 0.2080 & 15.6 & & & 1.18 & 0.238 & . \\
\hline & Matched & 0.2432 & 0.2409 & 0.5 & 65.7 & & 0.04 & 0.969 & . \\
\hline \multirow[t]{2}{*}{ INFO } & Unmatched & 0.440 & 0.4960 & -11.4 & & & -0.89 & 0.377 & . \\
\hline & Matched & 0.4234 & 0.4301 & -1.4 & 27.3 & & -0.10 & 0.919 & . \\
\hline \multirow[t]{2}{*}{ LANDHLD } & Unmatched & 0.8720 & 0.8160 & 13.2 & & & 1.22 & 0.224 & . \\
\hline & Matched & 0.8558 & 0.8491 & 1.6 & 73.6 & & 0.14 & 0.888 & . \\
\hline \multirow[t]{2}{*}{ ASSO } & Unmatched & 0.9360 & 0.960 & -7.2 & & & -0.85 & 0.395 & . \\
\hline & Matched & 0.9279 & 0.9301 & -0.7 & 70.2 & & -0.07 & 0.948 & . \\
\hline \multirow[t]{2}{*}{ CREDIT } & Unmatched & 0.560 & 0.4640 & 19.3 & & & 1.52 & 0.130 & . \\
\hline & Matched & 0.5675 & 0.5450 & 4.5 & 80.0 & & 0.34 & 0.737 & \\
\hline
\end{tabular}

Source: Author's survey data $(2016 / 17)$

The standardized bias before match and after match, the total bias reduction obtained by the matching procedure as shown at Table 4, Standardized difference in covariates before matching is in between of $1 \%$ and $19.3 \%$ in absolute value whereas the remaining standardized difference of covariates for almost all covariates lies between $0.5 \%$ and $18.4 \%$ after matching. This is fairly below the critical level of $20 \%$ suggested by Rosenbaum and Rubin (1985). Therefore, the process of matching creates a high degree of covariate balance between the member and non-member samples that are ready to use in the estimation procedure. The same to that, t-values also reveal that before matching and after matching all of the covariates are balanced and become statistically insignificant, suggesting that matching helps to reduce the bias associated with observable characteristics.

These results indicate that the matching procedure is able to balance the characteristics in the treated (members) and the matched untreated (non-members) groups. Hence, these results can be used to assess the impact of dairy enterprises on employment creation and income generation. This enables researcher to compare observed outcomes for treatments (members) with those of an untreated (non-members) groups sharing a common support region.

\subsubsection{Impact of Dairy Enterprises on Employment Creation}

The results of the nearest neighbour (4) matching algorithm confirm that there were difference between member and the non-member household's in terms of total annual employment created by households in number. A comparative analysis shows that member households were better than non-member households by creating employment opportunities for about 4 persons annually (i.e. 33.98\% higher than non-member households) and this gain was statistically significant at $1 \%$ probability level. In this case, the mean employment created by the 
member households was about 6 persons annually and that of the non-member households was about 2 persons annually. These results confirm that membership in dairy enterprises increased the employment creation of the households, which is the good remedy for number of jobless individuals in the study area.

\subsubsection{Impact of Dairy Enterprises on Income Generation}

According to the best matching algorithm estimates [i.e. nearest neighbour (4) matching algorithm] showed that being member in dairy enterprises had a positive and significant impact on the amount of household's total annual income received in Birr (Table 5). As the result indicated that the impact of being member in dairy enterprises was significant at 1\%. As expressed below in Table 3.4, the mean household's total income was about Birr 18,302.00 for member household's, while the corresponding figure for the non-member household's was Birr 5,962.00 and the average income difference between member and non-member households were Birr 12,339.00. It implies that the total annual income of the member household's was almost $32.57 \%$ higher than that of total annual income of the non-member household's. The results indicate that membership in dairy enterprises increased the total annual income of the household's, which is the god source of income for the household's to carve the problem of income scarcity.

Table 5. Average treatment effect on treated

\begin{tabular}{lllllccl}
\hline Variable & Sample & Member & Non-member & Difference & $\%$ & SE & t-value \\
\hline Employment creation & ATT & 6.1441 & 2.0878 & 4.0563 & 33.98 & 0.3060 & $13.26^{* * *}$ \\
Income generation & ATT & 18,302 & 5,962 & 12,339 & 32.57 & 1,444 & $8.54 * * *$ \\
\hline
\end{tabular}

Source: Author's survey data (2016/17)

\subsection{Sensitivity Analysis}

In observation studies, program intervention treat are not randomly assigned experiment units, randomization tests are not generally applicable. Thus to compensate for the lack of randomization; member and non-member units are matched on the basis of observed covariates. However, in most case possibilities remain of bias due to residual imbalance in unobservable covariates. Therefore, sensitivity analysis were carried out to check quality of comparison matching among member and non-member group with observed covariates and mainly to check robustness for unobserved covariates and the result indicates the ATT estimate result are insensitive.

In case the CIA fails in PSM it can be easily solved the pitfall using the comparison between the simulated and baseline ATTs estimates. Thus, for any given configuration of the parameters $P_{i j}$, the sensitivity analysis retrieves a point estimate of the ATT which is robust to the failure of the CIA implied by that particular configuration. Using a given set of values of the sensitivity parameters, the matching estimation is repeated many times and a simulated estimate of the ATT is retrieved as an average of the ATTs over the distribution of $U$. As it can be seen from the Table 6 provided below, though $U$ is associated with a large outcome effects $(\Gamma>1)$ and selection effects $(\wedge>1)$ for the nearest neighbour (4) matching algorithms, the overall simulated ATTs of each member of dairy enterprises are still too much closer to the baseline ATTs. Hence, both the values of outcome effect and selection effects are larger than unity each, and also the difference in percentage between the baseline ATTs and simulated ATTs are below 10\% make it stronger in the credibility of our estimated ATTs as well. The simulated ATT of each of the employment creation and income generation are too close to the baseline estimate. Obviously, this implies that it is only when $U$ is simulated to provide incredibly large outcome effect; the ATT can be driven far from the baseline estimates or even closer to zero. Thus, we can conclude that our impact estimates ATT are insensitive to unobserved selection bias and are a pure effect of membership in dairy enterprises. On the whole, all the results estimated support and strengthen the robustness of the matching analysis is the reliable conclusion. 
Table 6. Result of sensitivity analysis

\begin{tabular}{lllllll}
\hline Outcome variable & $\begin{array}{l}\text { Baseline } \\
\text { ATT }\left(\mathrm{A}_{1}\right)\end{array}$ & $\begin{array}{l}\text { Simulated } \\
\text { ATT }\left(\mathrm{A}_{2}\right)\end{array}$ & $\begin{array}{l}\text { Outcome } \\
\operatorname{effect}(\Gamma)\end{array}$ & $\begin{array}{l}\text { Selection } \\
\operatorname{effect}(\Lambda)\end{array}$ & $\begin{array}{l}\text { Absolute } \\
\operatorname{difference}\left(\mathrm{A}_{1}-\mathrm{A}_{2}\right)\end{array}$ & $\begin{array}{l}\text { Difference in \% } \\
\left(\mathrm{A}_{1}-\mathrm{A}_{2} / \mathrm{A}_{1}\right)\end{array}$ \\
\hline Employment creation & 13.26 & 13.25 & 13.25 & 89.08 & 0.01 & 0.07 \\
Income generation & 8.54 & 8.53 & 14.12 & 189.01 & 0.01 & 0.01 \\
\hline
\end{tabular}

Source: Author's survey data (2016/17)

\section{Conclusion and Recommendations}

The survey results showed that out of 385 sampled household heads $126(32.5 \%)$ were members and the remaining $259(67.5 \%)$ was non-members. From total sample household heads, the majority of them (74\%) were male-headed (the corresponding figures are $85 \%$ and $69 \%$ for members and non-members respectively). The mean age of the household heads was 32 years (it was 31 years for member and 34 years for non-member) household heads. The result depicts that the household heads found both in member and non-member category were found to be in active working age. The land holding size among both members and non-members group indicates that dairy enterprises members has small land size than non-members. From the member group 48.29\% household heads have land size below one hectare whereas, for non-member group 27.2\% household heads have land size below one hectare. Based on the land size possessed by non-member household heads respondent they are better than member of dairy enterprises in the study area.

The average household size of the sample household heads in the study area had large average household size of six persons with high mean total dependency ratio of 1.34. The average household size for member household heads was 7.34 persons while it was 5.06 persons for non-member household heads. From this we can conclude that, household size is the determinant factor of membership in dairy enterprises in the study area. The mean livestock holding in Tropical Livestock Unit (TLU) of the sample household heads was 6.45, where the minimum was 0 and the maximum was 32. The mean livestock holding for member households was 4.62 TLU and it was 8.29 TLU for non-member household heads. This means household heads with low livestock holding encouraged being member in dairy enterprises than the household heads owed large number of livestock.

The impact of dairy enterprises on employment creation and income generation between members and non-members was seen in this study clearly. A comparative analysis shows that member households were better than non-member households by creating employment opportunities for about 4 persons annually (i.e. $33.98 \%$ higher than non-member households) and this gain was statistically significant at $1 \%$ probability level. In this case, the mean employment created by the member households about 6 persons annually and that of the non-member households was about 2 persons annually. These results confirm that membership in dairy enterprises increased the employment creation of the households, which is the good remedy for number of jobless individuals in the study area. The impact of being member in dairy enterprises was significant at $1 \%$ probability level. Based on the result of PSM, the mean household's total income was about Birr 18,302.00 for member household's, while the corresponding figure for the non-member household's was Birr 5,962.00 and the average income difference between member and non-member households were Birr 12,339.00. It implies that the total annual income of member households was almost $32.57 \%$ higher than the total annual income of the non-member households.

The result showed that membership in dairy enterprises had a significant positive impact on employment creation and income generation and the impact estimates were found to be insensitive to unobserved selection bias. It is, therefore, essential to expand and strengthen development of dairy enterprises and the membership of households by giving special attention and necessary support to the sector in the study area. Hence, the findings of this study recommend the need for implementing different policies and strategies that separately target and address the dairy enterprises' that improves their impact on employment creation and income generation.

\section{Acknowledgement}

I would like to thank my God the Almighty for having given me the strength and wisdom and guiding me to complete this onerous tough research undertaking. I also wish to express my special gratitude and appreciation to my advisors Prof. Jema Haji, Dr. Endrias Geta and Dr. Lemma Zemedu, for their critical comments and guidance that lie behind the forms and content of this work. I am highly thankful to Haramaya University and Hadiya zone administration for the facilitation of logistics and budget for the successful accomplishment of this dissertation work. I would like to extend my deep sense of appreciation and respect to my beloved wife Roman Bekele and my son Fikir Abraham for their patience and love during the whole study time even they faced difficult times in 
my absence. I also thank my great brothers, sisters and friends for their encouragement throughout my study. Finally, it is always impossible to mention all; therefore, I would like to thank and accept my heartily admire for everyone who has helped me one way or the other.

\section{References}

Caliendo, M., \& Kopeinig, S. (2008). Some Practical Guidance for the Implementation of Propensity Score Matching. Journal of Economic Surveys, 22(1), 31-72. https://doi.org/10.1111/j.1467-6419.2007.00527.x

CSA (Central Statistical Authority). (2013). Population projection of Ethiopia for all regions at woreda level from 2014-2017. Federal Democratic Republic of Ethiopia, Addis Ababa, Ethiopia.

Dehejia, R. H., \& Wahba, S. (2002). Propensity score matching methods for non-experimental causal studies. The Review of Economics and Statistics, 84(1), 151-161. https://doi.org/10.1162/003465302317331982

FeMSEDA (Federal Micro and Small Enterprises Development Agency). (1997). Micro and small enterprises development strategy, Addis Ababa, Ethiopia.

Fikite, W., \& Endrias, G. (2015). Determinants of growth and diversification of micro and small enterprises. The case of Dire Dawa, Ethiopia. Journal of Developing Country Studies, 5(1), 61-75.

Hailay, A., Aregawi, G., \& Assmamaw, G. (2014). Determinants of micro and small enterprises growth in rural area. Journal of Economics and Sustainable Development, 5(19), 2222-2855.

Israel, G. D. (1992). Sampling the evidence of extension program impact. Program evaluation and organizational development, IFAS, University of Florida.

Kothari, C. R. (2004). Quantitative Techniques. Vikas Publishing House Pvt. Ltd., New Delhi.

MoFED (Ministry of Finance and Economic Development). (2016). Federal Democratic Republic of Ethiopia, Ethiopia's progress towards eradicating poverty: An interim report on poverty analysis study.

Rosenbaum, P. R., \& Rubin, D. B. (1983). The central role of the propensity score in observational studies for causal effects. Journal of Biometrika, 7, 41-55. https://doi.org/10.1093/biomet/70.1.41

Rosenbaum, P. (2002). Observational Studies, $2^{\text {nd }}$ edition. New York: Springer. https://doi.org/10.1007/978-1-4757-3692-2

Tariku, A. (2018). Review on factors affecting the performance of micro and small enterprise in Ethiopia. International Journal of Political Science and Development, 6(8), 275-279.

Tomas, C., Muluken, Z., Shimelis, T., \& Muralidhar, A. (2018). Examining significant factors in micro and small enterprises performance: Case study in Amhara region, Ethiopia. Journal of Industrial Engineering International, 14, 227-239. https://doi.org/10.1007/s40092-017-0221-y

Yaregal, T. (2018). The role of micro and small enterprises for poverty alleviation. International Journal of Research Studies in Agricultural Sciences, 4(12), 38-47.

Zemenu, A. (2014). Determinants of growth of enterprises in Mekelle City, Ethiopia. International Journal of Advance Research in Management Studies, 2(6), 149-157.

\section{Copyrights}

Copyright for this article is retained by the author(s), with first publication rights granted to the journal.

This is an open-access article distributed under the terms and conditions of the Creative Commons Attribution license (http://creativecommons.org/licenses/by/3.0/). 